\title{
Using proxies to calculate the carbon impact of investment into electricity network assets
}

Article

Accepted Version

Daniels, L., Coker, P., Gunn, A. and Potter, B. (2016) Using proxies to calculate the carbon impact of investment into electricity network assets. Applied Energy, 162. pp. 551-560. ISSN 0306-2619 doi:

https://doi.org/10.1016/j.apenergy.2015.10.111 Available at https://centaur.reading.ac.uk/45566/

It is advisable to refer to the publisher's version if you intend to cite from the work. See Guidance on citing.

To link to this article DOI: http://dx.doi.org/10.1016/j.apenergy.2015.10.111

Publisher: Elsevier

All outputs in CentAUR are protected by Intellectual Property Rights law, including copyright law. Copyright and IPR is retained by the creators or other copyright holders. Terms and conditions for use of this material are defined in the End User Agreement.

www.reading.ac.uk/centaur 
Central Archive at the University of Reading

Reading's research outputs online 


\title{
Using Proxies to Calculate the Carbon Impact of Investment into Electricity Network Assets
}

\author{
Laura Daniels ${ }^{\mathrm{a}}$, Phil Coker ${ }^{\mathrm{b}}$, Alice Gunn ${ }^{\mathrm{a}}$, Ben Potter ${ }^{\mathrm{c}}$ \\ ${ }^{a}$ Technologies for Sustainable Built Environments (TSBE) Centre, University of Reading, UK \\ ${ }^{b}$ School of the Built Environment, University of Reading, UK \\ ${ }^{c}$ Energy Research Lab, School of Systems Engineering, University of Reading, UK
}

\begin{abstract}
Replacement and upgrading of assets in the electricity network requires financial investment for the distribution and transmission utilities. The replacement and upgrading of network assets also represents an emissions impact due to the carbon embodied in the materials used to manufacture network assets. This paper uses investment and asset data for the GB system for 2015-2023 to assess the suitability of using a proxy with peak demand data and network investment data to calculate the carbon impacts of network investments. The proxies are calculated on a regional basis and applied to calculate the embodied carbon associated with current network assets by DNO region. The proxies are also applied to peak demand data across the 2015-2023 period to estimate the expected levels of embodied carbon that will be associated with network investment during this period. The suitability of these proxies in different contexts are then discussed, along with initial scenario analysis to calculate the impact of avoiding or deferring network investments through distributed generation projects. The proxies were found to be effective in estimating the total embodied carbon of electricity system investment in order to compare investment strategies in different regions of the GB network.
\end{abstract}

Keywords: embodied carbon, distributed generation, proxy, network investment deferral

\section{Introduction}

It is estimated that the transition to a low carbon electricity system for the GB electricity network could require investment of $8.8 \mathrm{bn}$ GBP in reinforcements on the Transmission Network (Tx) [1]. These network investments would have embodied carbon impacts due to the materials and construction activities associated with network assets, such as the installation and upgrade of cables and transformers. Investments in new network assets will aid and enable the transition to a low carbon electricity supply but their associated emissions should be quantified and taken into consideration when deciding on investment strategies.

The impact of Demand Side Management (DSM) or Distributed Generation (DG) projects on Network Investment has been investigated by a number of researchers, each taking a different focus, due to the number of ways that DG can affect the network. These impacts include minimising losses [2] and potentially deferring network investment by reducing peak demand

Email address: b.a.potter@reading .ac.uk (Ben Potter)
[3], and the financial impact associated with Network Investment Deferral has been calculated [4], [5] in several local models and the possibility of DSM and DG contributing to reduced investment costs and therefore emissions is discussed in several papers. However, there is often no attempt to quantify this environmental impact. For a DG owner or DSM project operator, assessing the environmental impact of their projects could become vital as carbon footprint reporting becomes mandatory. It is especially important for certain DG owners such as owners of standby generators (SG), which are often diesel fuelled. Diesel generators are the most commonly installed DG technology worldwide and are often used for network support through contracts with the SO to run at time of peak demand. Running diesel generators emits carbon locally, which can have a negative brand impact or financial impact depending on the company size and regulatory framework. The carbon emitted locally is higher than the average grid emissions factor in the GB electricity system. An average diesel generator emits $700 \mathrm{gCO}_{2} / \mathrm{kWh}$, whereas average grid emissions factors range from $430 \mathrm{gCO}_{2} / \mathrm{kWh}$ to $520 \mathrm{gCO}_{2} / \mathrm{kWh}_{\text {[6]. It is }}$ 
therefore important to consider the long term impacts of running diesel generators in supporting the electricity network.

Assessing the impact of Network Investment and Network Investment Deferral is challenging for an individual project-by-project basis as a Life Cycle Assessment (LCA) would need to be carried out, which is a data-intensive and time-consuming process. However, applying a proxy, or emissions factor, provides an estimate that could be used to evaluate and compare a range of different project options. A proxy is a factor used to convert one unit to another. Being able to apply a proxy to convert between investment and investment deferral to the amount of embodied carbon associated with that investment would allow for an estimate to be generated based on data that is readily available to either the Transmission Network System Operator (SO) or Distribution Network Operator (DNO).

It is therefore the aim of this paper to identify an appropriate proxy that can be used to estimate the embodied carbon associated with network assets, given either network investment or increase in peak demand over a given time, in order to consider the total carbon impact of running a DG unit in support of the electricity network. The GB system is used as a case study given the availability of peak demand data and investment data over a set period of time. The GB SO, National Grid, have contracts with owners of $743 \mathrm{MW}$ of diesel generators for network support [7], which are regularly used in times of peak demand. National Grid have recently acknowledged the importance of calculating the carbon associated with network support [8]. These calculations are not complete without an assessment of the embodied carbon impact of delaying network investment.

\section{Motivation}

There are two key benefits of the proxy described above for the SO and DNO: they can calculate the embodied carbon cost of peak demand growth under current investment strategies; and they can use the proxy to assess other options for peak load reduction for potentially lower carbon solutions.

At present in the GB system, the second benefit may be more applicable to the SO due to the fact that the DNO cannot arrange contracts for ancillary services like the SO can. However, in the future, DNOs may have some control over using different methods to manage their network investment requirements and they may wish to evaluate the carbon impacts of several options before deciding on an investment strategy. In addition to this, DG owners may wish to understand the carbon impact of running their DG on the network as part of their CSR policy or environmental strategy,

The use of DG and DSM is likely to increase as the transition to a low carbon electricity supply progresses. The running of company owned DG and SG may be incentivised inherently by the electricity pricing structure, as is the case in the GB electricity market [9], or through formal contracts with the SO in times of extreme peak demand. However, when running different forms of DG, in particular SG, carbon emissions may be emitted locally. The associated carbon emissions can have a branding impact as well as a financial impact for the DG owners. Although the contracts and inherent incentives are designed to cover fuel costs, they are not designed to cover the cost of emissions to the DG owner. For example in the UK, larger electricity consumers on a half hourly metered tariff pay the Carbon Reduction Commitment (CRC) at 16.40GBP per tonne [10]. This carbon charge has increased year on year since 2012, when the charge was 12GBP per tonne [11]. Due to these charges, quantifying the carbon impact could become a deciding factor for companies considering running their generators for grid support. A driver for some of the Network Investment Deferral work quantifying the economic benefits has been distribution of benefits to DG owners in order to encourage those most beneficial to the network. This understanding is also a motivation and potential application of the work [12].

There is a range of literature that discusses Network Investment Deferral but most of it focuses on the financial impact to DNOs, although there is a body of work that talks about the potential for transmission network level benefits on an aggregated level. Certain papers discuss the potential for DG to defer network investment as the context for assessing DG impacts [13-15]. Most of the work fails to account for the fact DG has an emissions impact on the network, although some aims to integrate emissions to some degree [4]. However, more often than not the focus is on financial impacts.

A number of previous studies have attempted to quantify the potential resource in a number of different manners. Difference in Return on Investment (ROI) between DG and Network Investment [5], [16, 17] and Capital expenditure by the Distribution Network Operator (DNO) [18-22] are the most commonly calculated variables. However, some studies have identified methods to calculate the length of investment deferral in years [23, 24] and allowable additional load growth due to DG [25] or a combination of the above [4, 12, 26].

In addition to the range of indicators used within the literature, there is also a difference in aims; some literature focuses on modelling or quantifying impacts 


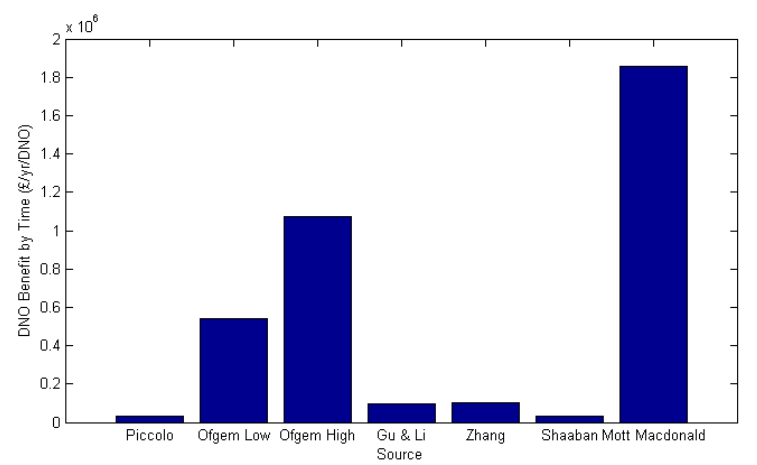

Figure 1: Comparison of Annual DNO Benefits calculated in Literature

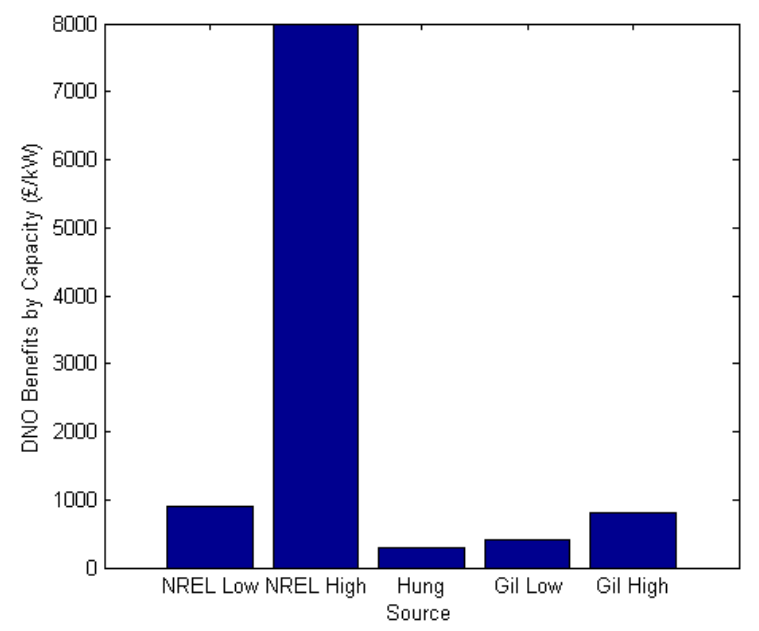

Figure 2: Comparison of DNO Benefits per kW of DG Capacity as found in Literature

whereas others, particularly those looking at a range of indicators, aim to optimise DG sizing, location, technologies and penetration levels. This range of indicators and aims makes comparing data and results challenging. While some papers choose to calculate the total savings across a DNO region, as shown in Figure 1, others calculate the value of a certain capacity of DG. Figure 2 shows these results as well as results from some other papers converted to similar units.

Figure 1 and Figure 2 show that there is a wide range of results available in the literature, due to the scenarios analysed and the assumptions used in each analysis. Figure 1 and Figure 2, for example, highlight that within one paper, a range is seen in accordance with the amount of time an asset investment could be delayed due to a DG capacity. This study also differentiates between the value of deferring different network assets by stating that delaying investments into lines and feed- ers has a far higher value than delaying investment into transformers and substations [27].

Most studies that address electricity networks discuss the LCA of generating technologies rather than the network assets themselves. Some incorporate network assets and losses as part of assessing generation technologies [28, 29] but it is only [30] that focuses on the embodied emissions of network assets. The study is based on the GB transmission network and calculates total embodied carbon of a range of different assets. The embodied carbon for overhead lines (OHL) and underground cables (UGC) are used in the forming proxies for the GB network in this paper.

\section{Network Investment to Carbon Proxies}

\subsection{Method and Approach}

Proxies are developed for the GB system. The high voltage electricity network is operated by the SO (National Grid Electricity Transmission plc) and the low voltage network is operated by 14 licensed DNOs each responsible for a regional distribution area, as shown in Table 1. The SO and DNOs are natural monopolies regulated by the Office for Gas and Electricity Markets (Ofgem).

The investment period used for the development of the proxies is the price control period, RIIO-ED1 (for Distribution) and RIIO-T1 (for Transmission), which both cover an 8 year period from 1 April 2015 to 31 March 2023. This price control period is the first using the new RIIO framework, which has been designed to address the future network challenges. RIIO stands for Revenue $=$ Incentives + Innovation + Output and it sets out financial incentives to encourage innovation and meet future social and environmental challenges at a fair cost to consumers.

As part of the RIIO process network operators are required to submit detailed and well justified business plans of their strategy for that period to Ofgem which meet the RIIO objectives. Ofgem then scrutinises these plans through a transparent consultation process [31]. This level of detail and transparency provides a robust source of data on network growth, cost and predicted demand.

Two approaches are used in this paper to calculate proxies. Ofgem regulate the spending of the GB DNOs and SO and publish a maximum allowable spend per unit of network asset based on information provided by DNOs and the SO [32, 33]. The first proxy method uses the allowable investment per $\mathrm{km}$ of new cable combined with carbon data from [30], and the second proxy 
Table 1: Distribution Network Operators in Great Britain

\begin{tabular}{ll}
\hline Region & DNO Name \\
\hline 10 & Eastern Power Networks \\
11 & Western Power -East Midlands \\
12 & London Power Networks \\
13 & Scottish Power Manweb \\
14 & Western Power - West Midlands \\
15 & Northern Power Grid (North East) \\
16 & Electricity North West \\
17 & Scottish Hydro \\
18 & Scottish Power Distribution \\
19 & South Eastern Power Networks \\
20 & Southern Electric Power Distribution \\
21 & Western Power - South Wales \\
22 & Western Power - South West \\
23 & Northern Power Grid (Yorkshire) \\
\hline
\end{tabular}

method uses total investment data from the RIIO-ED1 period and the new cable requirements over the same period. For the Transmission Network, only the first method can be used due to currently available data. For the Distribution Network, both methods can be used in order to calculate two separate proxies for comparison. The second method may overestimate the associated carbon due to the fact that investment may not solely be for network assets but could be used where the exact cost of upgraded assets is unknown. Initially the model is a tool for SO and DNO to assess the impacts of their asset investment on their carbon reporting. The proxies are applied to investment data from RIIO-ED1/RIIO-T1 and peak demand data from the same period. This estimates the embodied carbon associated with the new network assets required during this investment period.

Figure 3 highlights the data flows for each method showing that investment data, new cable requirements and embodied carbon of the assets is required for one method, but only the embodied carbon and publically available allowable investment data is required for the second. Although the first method has one additional calculation step, it is more likely that the investment data can be used to aggregate the investment into different asset types across a DNO region. Embodied Carbon, as referenced in Figure 3 covers many components of the environmental impact associated with network investment including construction, maintenance, operation and decommissioning, as taken from Harrison's work [30]. However, the method used in this paper does not include some impacts of network investment. Network upgrades, for example, are difficult to quantify and information regarding their cost and extent is not publicly available. As the scope of this study is to establish a method to create a replicable proxy, addition of this data would be inappropriate.

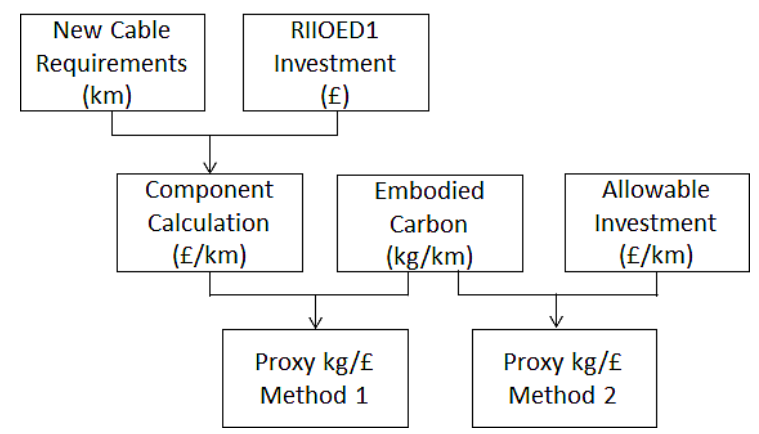

Figure 3: Data Flows using Predicted Investment and Allowable Investment

\subsection{Transmission Network Calculations}

Table 2: Average Carbon Intensities of Transmission Network Assets

\begin{tabular}{llll}
\hline Asset & $\mathrm{tCO}_{2}$ & $\begin{array}{l}\text { TSO length } \\
(\mathrm{km})\end{array}$ & $\begin{array}{l}\text { Carbon Intensity } \\
\mathrm{tCO}_{2} / \mathrm{km}\end{array}$ \\
\hline OHL & 2600000 & $22670[30]$ & 114.69 \\
$\mathrm{UGC}$ & 700000 & $887[30]$ & 789.18 \\
\hline
\end{tabular}

Table 3: Allowable Costs per Unit of Transmission Network Asset

\begin{tabular}{lll}
\hline Asset type & Unit & Cost per Unit \\
\hline Overhead Line & $\mathrm{km}$ & $£ 1,200,000[32]$ \\
Underground Cable & $\mathrm{km}$ & $£ 16,400,000[32]$ \\
\hline
\end{tabular}

Carbon and asset data from [30] is used to calculate an average carbon intensity for each type of cable which are shown in Table 2. This is an average across all types of cable although different voltage levels do require different material and therefore have different embodied carbon impacts. In order to calculate a proxy that can be used, investment per unit is required. The SO is subject to a Price Control Review and asset investment data is provided by Ofgem. The allowable OHL Investment per unit is given in the most recent review and shown in Table 3 [32].

Although at SO level, asset data for transformers and substations is available, they are not included because of the difficulty in comparing non similar units and in order to keep the method consistent with the Dx proxy. 
OHL and UGC are considered internally similar - despite different voltage levels having different material and construction requirements. However, this proxy is supposed to be used as a guide and therefore an average for each cable type is used.

By definition, an emissions proxy as used in this paper is the ratio of the carbon intensity of an asset to the cost of an asset. This emissions proxy, on the simplest level, could be calculated using averages or estimates across a whole network - either transmission level or distribution level. However, it is more suitable to define proxy components for different network asset types because the carbon intensities and costs vary for different assets and therefore to calculate an average Tx Emissions Proxy, Equation 1 and Equation 2 must be used to calculate a component for the proxy from each asset. Equation 1 and Equation 2 are used for Method 1, which uses an asset cost. The cost is defined as an investment intensity - a cost per unit length of asset. When applying data from Table 2 and Table 3 to Equation 1 and Equation 2, a proxy for the OHL and UGC can be calculated and these are then combined in the ratio of asset data in Table 2 using Equation 3 to give an overall average proxy for the Tx level, shown in Table 4.

$$
\begin{gathered}
P C_{O H L}=\frac{O H L_{\mathrm{CO}_{2}}}{O H L_{G B P}} \\
P C_{U G C}=\frac{I n t_{C O_{2}}}{I n t_{G B P}} \\
E P_{T x}=\frac{P C_{O H L} L_{O H L T x}+P C_{U G C} L_{U G C T x}}{L_{O H L T x}+L_{U G C T x}}
\end{gathered}
$$

Table 4: Transmission Network Proxy

\begin{tabular}{ll}
\hline Asset type & $\begin{array}{l}\text { Carbon Proxy } \\
(\mathrm{kg} / \mathfrak{£})\end{array}$ \\
\hline Transmission OHL & 0.10 \\
UGC & 0.05 \\
Transmission Network & \\
$(96 / 4$ split OHL/UGC) & 0.09 \\
\hline
\end{tabular}

\subsection{Distribution Network Calculations}

Initially, the embodied carbon of the assets currently owned and operated by each DNO region is calculated and shown in Figure 4 .

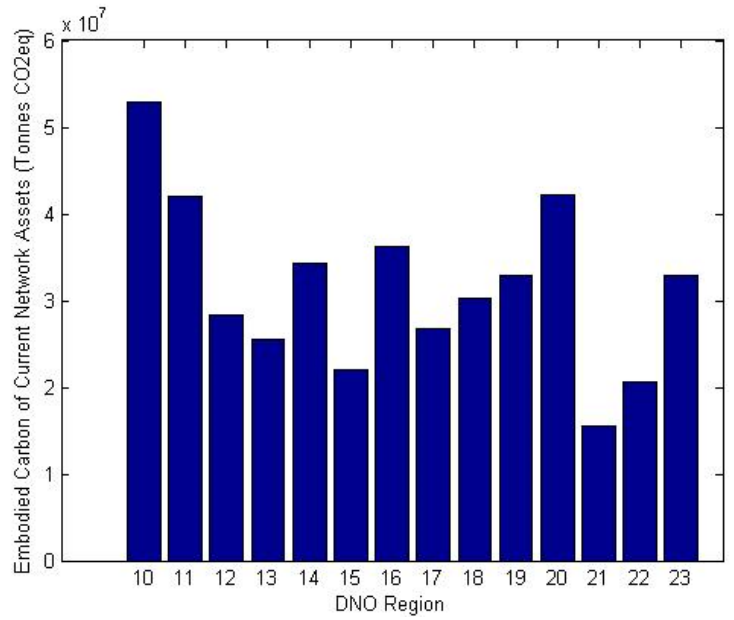

Figure 4: Estimated Embodied Emissions of Current Distribution Network Assets

Table 5: Allowable Investment per Unit Distribution Network Assets

\begin{tabular}{lcl}
\hline Asset type & Unit & Cost per Unit \\
\hline Low Voltage & & \\
Distribution Main UGC & $\mathrm{km}$ & $£ 98,400$ \\
Low Voltage & & \\
Distribution OHL Rebuild & $\mathrm{km}$ & $£ 28,400$ \\
\hline
\end{tabular}

The allowable investment data is used to calculate the proxy using Method 1 with the same approach as the Tx proxies. Asset investment costs are approved by Ofgem on a regular basis. The costs for each unit of DNO asset during RIIO-ED1 are taken from Ofgem and are shown in Table 5 $(\mathfrak{f} / \mathrm{km})$. The Tx carbon intensities $(\mathrm{kg} / \mathrm{km})$ from [34] are then used to create proxy components for UGC and OHL using the same method as for the Tx proxy components shown in Equation 1 and Equation 2 . These are combined in the ratio of the UGC/OHL for each DNO, in the same approach as with the Tx Proxy shown in Equation 3 to give proxies for each network asset type as shown in Table 6. An average proxy for the whole GB Distribution Network has also been calculated using the ratio in the average split of the DNO assets across GB shown in Equation 4. The results, shown in Table 6 shows that the ratio of assets impacts the overall DNO proxy, as the proxy components for each asset vary significantly.

$$
E P_{D x 1}=\frac{P C_{O H L} L_{O H L D x}+P C_{U G C} L_{U G C D x}}{L_{O H L D x}+L_{U G C D x}}
$$

For comparison, the same proxy can also be calcu- 
Table 6: Proxies for Distribution Asset Types and a Distribution Wide Proxy

\begin{tabular}{ll}
\hline Proxy Description & $\begin{array}{l}\text { Carbon Proxy } \\
(\mathrm{kg} / \mathfrak{f})\end{array}$ \\
\hline $\begin{array}{l}\text { Low Voltage Main UGC } \\
\text { Low Voltage Main OHL Rebuild }\end{array}$ & 8.04 \\
$\begin{array}{l}\text { Distribution Network } \\
\text { (based on 33OHL/66UGC split) }\end{array}$ & 6.63 \\
\hline
\end{tabular}

lated using Method 2 - using new cable requirements and published investment over the RIIO-ED1 period. Asset data is taken from the DNO region RIIO-ED1 business plans, along with other documents published by DNOs and is shown in Table 7 . Due to the varying nature of data provision, only OHL and UGC are shown as the data for transformers and substations is incomplete.

Electricity North West published the new requirements for cable investment between 2010 and 2015 [35]. These are used to calculate the annual asset requirements for the other DNOs based on the assumption that the Electricity North West data is representative of new annual asset requirements as a percentage of existing assets. The estimated new cable requirements over the RIIO-ED1 period are extrapolated from the estimated DNO annual asset requirements as shown in Table 7 based on data made available by the DNOs [3647.

Table 7: DNO Asset Data and Estimated New Asset Requirements

\begin{tabular}{lllll}
\hline DNO & OHL & UGC & $\begin{array}{l}\text { New OHL } \\
\text { required } \\
(\mathrm{km})\end{array}$ & $\begin{array}{l}\text { New UGC } \\
\text { required } \\
(\mathrm{km})\end{array}$ \\
\hline 10 & 34000 & 62000 & 2877 & 282 \\
11 & 22000 & 50000 & 1862 & 227 \\
12 & 0 & 36000 & 0 & 164 \\
13 & 18286 & 29714 & 1547 & 135 \\
14 & 24000 & 40000 & 2031 & 182 \\
15 & 14800 & 25800 & 1252 & 117 \\
16 & 13000 & 44000 & 1100 & 200 \\
17 & 16251 & 31497 & 1375 & 143 \\
18 & 21714 & 35286 & 1837 & 160 \\
19 & 12000 & 40000 & 1015 & 182 \\
20 & 27173 & 49626 & 2299 & 226 \\
21 & 18000 & 17000 & 1523 & 77 \\
22 & 28000 & 22000 & 2369 & 100 \\
23 & 13400 & 39800 & 1134 & 181 \\
\hline
\end{tabular}

Table 8: DNO Investment Data from RIIO-ED1 Period

\begin{tabular}{llll}
\hline DNO & $\begin{array}{l}\text { Investment } \\
\text { Total } \\
\text { Total } \\
(£ M)\end{array}$ & $\begin{array}{l}\text { Load } \\
\text { Related } \\
\text { Investment } \\
(£ M)\end{array}$ & $\begin{array}{l}\text { Annual } \\
\text { Load } \\
\text { Investment } \\
(£ M)\end{array}$ \\
\hline 10 & 1500 & 900 & 112.5 \\
11 & 854.5 & 267.2 & 33.4 \\
12 & 1300 & 700 & 87.50 \\
13 & 1069.1 & 213.3 & 26.66 \\
14 & 862.2 & 198 & 24.75 \\
15 & 458.7 & 184.3 & 23.04 \\
16 & 1219 & 899 & 112.38 \\
17 & 415.3 & 140 & 17.5 \\
18 & 705.7 & 145.2 & 18.15 \\
19 & 1000 & 400 & 50.0 \\
20 & 1005.2 & 297.4 & 37.18 \\
21 & 445.5 & 48.6 & 6.08 \\
22 & 659.8 & 84.7 & 10.59 \\
23 & 736 & 322.6 & 40.33 \\
\hline
\end{tabular}

Each DNO has published a business plan for the RIIO-ED1 period of 2015-2023. Investment data from these plans for each DNO region are shown in Table 8 . Also shown in Table 8 is the calculated annual load investment during this period. This calculation assumes that the investment is shared evenly each year throughout the RIIO-ED1 period and assumes that load investment is investment in cables, pylons and transformers. This data highlights the difference in DNO regions with a range of annual load investment. Data from Table 7 and Table 8 can then be multiplied by the Tx carbon intensities from [30] to give annual embodied emissions of investment and the generalised proxy is developed by combining with annual load related investment as shown in Equations 5, 6 and 7. Regional Proxies are then calculated according to Method 1 and Method 2 and these results are shown in Table 9 in order to compare the two methods. Table 9 also highlights the regional dependency of the proxies, due to the differing composition and operation of each DNO region.

$$
\begin{gathered}
E P_{D x 2}=\frac{L_{O H L D x}}{L_{O H L D x}+L_{U G C D x}}\left(P C_{O H L 2}+P C_{U G C 2}\right) \\
P C_{O H L 2}=\frac{N C R_{O H L} O H L_{G B P}}{L R I_{R I I O E D 1}}
\end{gathered}
$$




$$
P C_{U G C 2}=\frac{N C R_{U G C} U G C_{G B P}}{L R I_{R I I O E D 1}}
$$

Table 9: DNO Specific Proxies for Finance to Carbon

\begin{tabular}{lll}
\hline DNO & $\begin{array}{l}\text { Proxy Method 1 } \\
(\mathrm{kg} / \mathfrak{f})\end{array}$ & $\begin{array}{l}\text { Proxy Method 2 } \\
(\mathrm{kg} / \mathfrak{f})\end{array}$ \\
\hline 10 & 6.61 & 4.91 \\
11 & 6.80 & 11.76 \\
12 & 8.02 & 1.48 \\
13 & 6.50 & 10.65 \\
14 & 6.53 & 15.21 \\
15 & 6.57 & 10.25 \\
16 & 7.11 & 2.53 \\
17 & 6.66 & 15.47 \\
18 & 6.50 & 18.58 \\
19 & 7.10 & 5.20 \\
20 & 6.61 & 11.88 \\
21 & 5.97 & 38.79 \\
22 & 5.79 & 33.12 \\
23 & 7.02 & 6.77 \\
\hline
\end{tabular}

Calculating individual DNO proxies allows for the fact that DNO regions need to invest differently depending on the age and nature of their assets. It does not allow for geographic differences within the DNO region where the values could be much higher or much lower. In some recently upgraded areas or DNO regions, investment could be less, as the network may already be designed to account for increase in peak demand in previous upgrades. It is for this reason that the proxies are not suitable for calculating the impact of a single DG or DSM project, because the network at a very local scale will be misrepresented by the average factors across the region.

\section{Application of Proxies for Embodied Carbon}

\subsection{Transmission Network}

For the transmission network the proxy has been used to calculate the level of embodied carbon associated with the load related investment due over the RIIO-T1 period. The load related investment between 2015 and 2023 is estimated at $£ 4,859,300,000$. This investment figure and the proxy found in Table 4 are applied to Equation 8 to show that the embodied carbon associated with the investment during the RIIO-T1 8 year period is $456.3 \mathrm{mT} \mathrm{CO}_{2}$, which will be compared against the Distribution level results in the next section.

$$
E E_{T x}=I_{R I I O T x} E P_{T x}
$$

\subsection{Distribution Network}

There are two applications of the proxies; the first is a basic application of the proxy to the annual load investment. If the investment is known then Equation 9 can be used.

$$
E E_{D x}=I_{R I I O D x} E P_{D x}
$$

If no investment data is known, the method of calculating the embodied emissions depends on the data available. The investment can be calculated by applying the Investment Allowance [33] to required network asset replacements for a given period as shown in Equation 10 The investment could also be calculated using the increase in peak demand over a given period, combined with the calculated Dx Investment Proxy, calculated as in Equation 11.

$$
\begin{gathered}
I_{R I I O D x 1}=N C R_{O H L} O H L_{G B P}+N C R_{U G C} U G C_{G B P} \\
I_{R I I O D x 2}=\Delta P D_{D x} I P_{D x} \\
I P_{D x}=\frac{L R I_{R I I O D x}}{\Delta P D_{D x}}
\end{gathered}
$$

The Dx Investment Proxy is calculated using Equation 12 and gives the amount of investment required for each MW increase in peak demand and the calculated proxy for each DNO is given in Table 10 , along with the data used to calculate them from the RIIO-ED1 business plans. For the RIIO-ED1 period these methods provide the same results because the data used for calculating the investment factor and the emissions factor is for the RIIO-ED1 period.

This investment proxy can now be applied over any period of time, and can be used to assess future scenarios to determine the impact that projects such as DSM or DG will have on embodied carbon due to network investment.

As with previous calculations, linear investment through the RIIO-ED1 investment period is assumed. Where data is unavailable for peak demand in 2023, an average percentage increase of $7.3 \%$ is applied from other DNO data. Where data is unavailable for 2015 


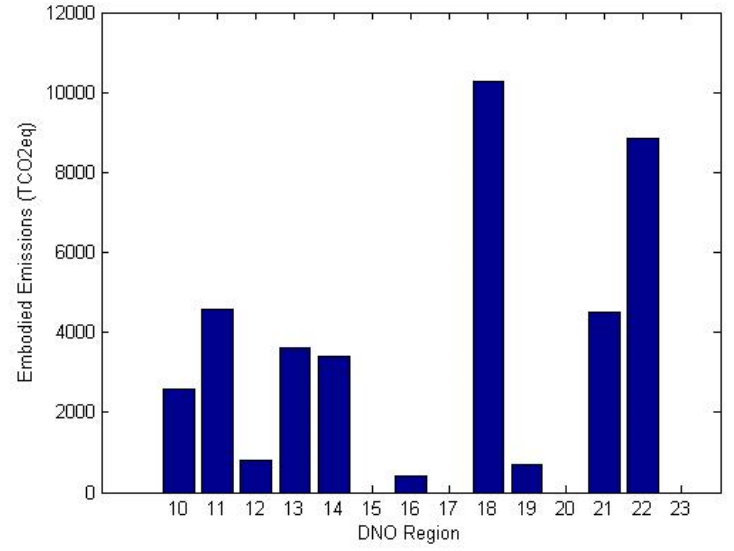

Figure 5: Embodied Emissions of RIIOED-1 Investment

Table 10: DNO Investment and Demand Data and Calculated Investment Proxies

\begin{tabular}{llll}
\hline DNO & $\begin{array}{l}\text { Annual Load } \\
\text { Investment } \\
(£ \mathrm{M})\end{array}$ & $\begin{array}{l}\text { Increase in } \\
\text { Peak } \\
(\mathrm{MW})\end{array}$ & $\begin{array}{l}\text { Investment } \\
\text { Proxy } \\
(£ / \mathrm{MW})\end{array}$ \\
\hline 10 & 112.5 & 528 & 1704545 \\
11 & 33.4 & 390 & 684449 \\
12 & 87.5 & 546 & 1282051 \\
13 & 26.7 & 338 & 631065 \\
14 & 24.8 & 224 & 883463 \\
15 & 23.0 & & \\
16 & 112.4 & 156 & 5778430 \\
17 & 17.5 & & \\
18 & 18.2 & 552 & 263043 \\
19 & 50.0 & 135 & 2962963 \\
20 & 37.2 & & \\
21 & 6.1 & 116 & 418233 \\
22 & 10.6 & 267 & 317194 \\
23 & 40.3 & & \\
\hline
\end{tabular}

and 2023, as is the case for four DNO regions, the table is left blank and no additional calculations are carried out. In the cases where data is available, Equation 9 is applied to calculate the embodied emissions associated with the investment by each DNO made throughout the RIIO-ED1 period. The results, shown in Figure 5, range from less than $1000 \mathrm{TCO}_{2}$ to over $10000 \mathrm{TCO}_{2}$ which highlights the importance of looking at the problem by each DNO region.

\section{Application of Proxies for Investment Scenarios}

\subsection{Investment Options Available}

The Distribution level calculations shown in the paper so far are used to show an initial calculation of the embodied carbon associated with a period of network asset investment. However, in future it would be useful for DNOs to be able to use the proxies to assess the differing impacts of a range of strategies to either reinforce the network or reduce peak demand before investments are made.

One of the main alternatives to investment in network upgrades is to reduce the peak demand. Either the peak demand is reduced to avoid network investment, or the peak demand growth is slowed to defer network investment. At Tx or Dx level, the main options are to run DG technologies at peak times, or to reduce load with DSM measures with consumers.

Many of the DG units already installed are standby generators (SG). Therefore the impact of carbon is an important factor for owners of these units, who are often not the distribution utilities, particularly in the GB market. Looking forward, this factor will be particularly true as these SG units may be formally contracted capacity for the System Operator (SO). Although SG units are not recognized as generation in the GB system in the SO Ten Year Statement [48], they do play a role in the network through ancillary services such as Short Term Operating Reserve (STOR), where they contribute $0.5 \mathrm{GW}$ of the capacity for this ancillary service [7]. In order to fully assess the carbon impacts, particularly of SG units, further model developments are required to account for the operational carbon emitted from the burning of fuel.

Currently, SG units would only be considered financially viable during times of peak demand, as signalled by pricing for large electricity consumers and the case study used here therefore assumes that SG units run at times of peak demand. This is intended to provide context for the applications of the proxies. In reality, the future smart grid could change the way in which SG units and other DG equipment is run and many scenarios could be investigated further.

\subsection{Initial Scenario Analysis}

\subsubsection{Operational Carbon}

In order to calculate the embodied carbon impact of any alternatives to network investment such as DG or DSM, the operational carbon impact of any DG or DSM measure must be calculated for the run hours it is used 
to support the network. For some forms of DG, operational carbon can present a challenge for the owners as is the case for diesel standby generators. For other forms of DG, which may include CHP and renewable micro-generation, there may be little or negligible operational carbon impacts for the DG owners. However, these other DG types may require new installation with an associated embodied carbon impact. The study presented in the following sections looks at existing standby diesel generators and so the embodied carbon of the generator is therefore considered negligible as the carbon has been previously emitted for a different purpose (i.e. in case of power failure).

To calculate the operational emissions impact of running generators, Equations 13 and 14 are used. When DG runs at peak times, less electricity is delivered from the electricity grid by traditional means. Therefore, the operational carbon is the difference between the local emissions and the avoided electricity grid emissions. The displaced grid emissions are calculated using grid emissions factors, which account for the generating capacity running at the time. These grid emissions factors change throughout the time of day and time of year depending on the demand and available generating capacity. In order to calculate the displaced emissions, the emissions factor in Equation 14 should account for the generation running at peak periods. However, this Peak Emissions Factor (PEF) cannot always be calculated for grid systems and often Average Emissions Factors (AEF) are used. Because the PEF will be higher than the AEF, the total operational carbon impact of running diesel generators cannot be truly known.

$$
O E_{D G}=C_{D G} E F_{D G} T_{D G}
$$

$$
D G E=C_{D G} E F_{G} T_{D G}
$$

\subsubsection{Calculations}

Electricity generation costs differ throughout the day and year depending on the demand and the available supply. These costs are reflected in electricity prices for customers on a Half Hourly $(\mathrm{HH})$ tariff. In Great Britain (GB) there are a number of components that contribute to the final electricity charge. These components, including charges to account for the use of the Transmission Network and Distribution Network vary by time, season and region. The Distribution Use of System (DUoS) charges are different at different times of day, with three distinct time periods for each DNO representing a different charging band; red, amber or green. Electricity prices can treble during the peak red DUoS period.

Table 11: Annual DNO Red DUoS Hours

\begin{tabular}{ll}
\hline DNO & $\begin{array}{l}\text { Red DUoS } \\
(\mathrm{hr} / \mathrm{yr})\end{array}$ \\
\hline 10 & 780 \\
11 & 780 \\
12 & 1560 \\
13 & 780 \\
14 & 780 \\
15 & 910 \\
16 & 520 \\
17 & 780 \\
18 & 780 \\
19 & 780 \\
20 & 780 \\
21 & 650 \\
22 & 520 \\
23 & 910 \\
\hline
\end{tabular}

For an SG unit, this means the most profitable running schedule is to generate electricity during the Red DUoS periods each day. These vary between DNOs and a summary is shown in Table 11. For the initial calculations, it is assumed that the DG is run in every Red DUoS band period and therefore Table 11 also represents the annual run hours of the DG.

To assess a study diesel generator, the DG Emissions Factor is assumed to be $710 \mathrm{~kg} / \mathrm{MWh}$, combining data from the CRC Energy Efficiency Scheme Guidance [11] and standard fuel consumption charts for diesel generators. As the CRC Guidance is used to calculate DG Emissions Factor, the Grid Emissions Factor from the same document is used. For the initial investigation, it is assumed that the SG unit is $1 \mathrm{MW}$ in capacity. Equations 13 and 14 are applied and results are given in Table 12. Table 12 shows that if just operational carbon is considered, SG units produce higher levels of emissions than the grid emissions they displace annually.

In order to combine these operational impacts with embodied carbon impacts, the annual results are initially applied across the eight year period spanned by RIIO-ED1. Asset Embodied Carbon Saved will be equivalent to the product of the DNO specific Carbon Proxy (Table 9), the DG capacity and the DNO specific Investment Proxy (Table 10). The results, in Table 13 . show that the embodied carbon savings over the RIIOED1 period could outweigh the additional operational 
Table 12: Standby Generator Operational Carbon Calculations

\begin{tabular}{llll}
\hline DNO & $\begin{array}{l}\text { Annual } \\
\text { DG } \\
\text { Emissions } \\
\text { (tonnes) }\end{array}$ & $\begin{array}{l}\text { Annual } \\
\text { Displaced } \\
\text { Grid Emissions } \\
\text { (tonnes) }\end{array}$ & $\begin{array}{l}\text { Annual Net } \\
\text { Operational } \\
\text { Carbon } \\
\text { (tonnes) }\end{array}$ \\
\hline 10 & 553.8 & 405.6 & 148.2 \\
11 & 553.8 & 405.6 & 148.2 \\
12 & 1107.6 & 811.2 & 296.4 \\
13 & 553.8 & 405.6 & 148.2 \\
14 & 553.8 & 405.6 & 148.2 \\
15 & 646.1 & 473.2 & 172.9 \\
16 & 369.2 & 270.4 & 98.8 \\
17 & 553.8 & 405.6 & 148.2 \\
18 & 553.8 & 405.6 & 148.2 \\
19 & 553.8 & 405.6 & 148.2 \\
20 & 553.8 & 405.6 & 148.2 \\
21 & 461.5 & 338.0 & 123.5 \\
22 & 369.2 & 270.4 & 98.8 \\
23 & 646.1 & 473.2 & 172.9 \\
\hline
\end{tabular}

carbon emitted by the standby generators running during the peak Red DUoS periods. The extent of this in each DNO is shown in Figure 6

Table 13: RIIO-ED1 Embodied Carbon and Operational Carbon Results

\begin{tabular}{lll}
\hline DNO & $\begin{array}{l}\text { Embodied Saved } \\
\text { Carbon RIIO-ED1 } \\
\text { (tonnes) }\end{array}$ & $\begin{array}{l}\text { Net Operational } \\
\text { Carbon RIIO-ED1 } \\
\text { (tonnes) }\end{array}$ \\
\hline 10 & 11267.04 & 1185.6 \\
11 & 4654.253 & 1185.6 \\
12 & 10282.05 & 2371.2 \\
13 & 4101.923 & 1185.6 \\
14 & 5769.013 & 1185.6 \\
15 & 0 & 1383.2 \\
16 & 41084.64 & 790.4 \\
17 & 0 & 1185.6 \\
18 & 1709.78 & 1185.6 \\
19 & 21037.04 & 1185.6 \\
20 & 0 & 1185.6 \\
21 & 2496.851 & 988 \\
22 & 1836.553 & 790.4 \\
23 & 0 & 1383.2 \\
\hline
\end{tabular}

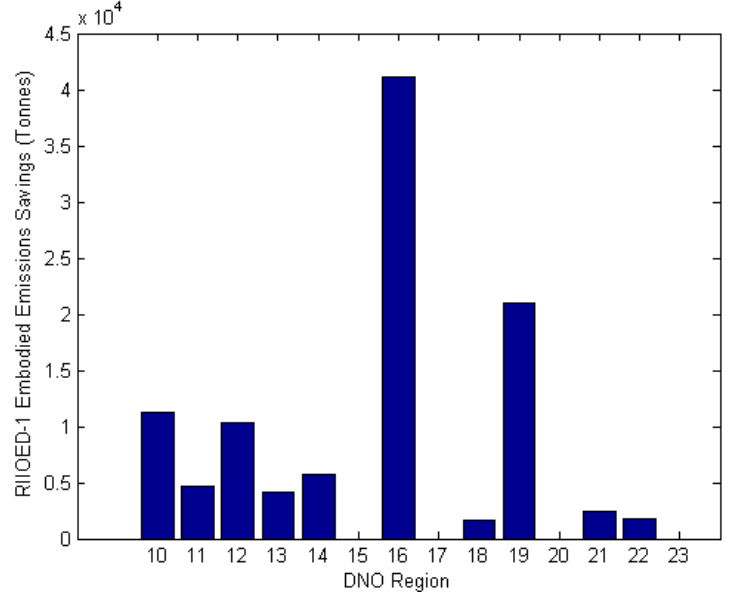

Figure 6: RIIO-ED1 Net Carbon Savings

\section{Discussion}

It is important to quantify the carbon impact of network investment and the potential impact of deferring or avoiding investment in the network in order to effectively plan network investment strategies and DG incentive schemes. Full life-cycle assessment is difficult and time consuming on a project-by-project basis and so there is a significant benefit to the use of a proxy or emissions factor to estimate financial investment figures. The proxies differ depending on the ratio between OHL and UGC as these represent different costs and embodied carbon levels, which means that regional proxies are useful to differentiate between regions with higher proportions of OHL or UGC. In the GB network, regional proxies are calculated by DNO region, as shown in Table 9 as calculated by two proposed methods.

It is assumed that the DG/DSM measures are operated over the peak demand period. In the current market, this period is the most likely time that controllable DG will operate, particularly if they are commercially owned due to the inherent incentives offered in the electricity pricing structure. Non-controllable DG, for example renewable micro-generation such as solar PV, may not operate on a similar schedule. As the focus of this work was SG units, it is a reasonable assumption that the peak charging period covered the majority of running hours of the DG units. However, if this model were extended to account for other types of DG or to look to the future where a smart grid may run DG units at different times of the day, the contribution of the DG to the DNO peak demand would need to be considered.

The proxy uses investment cost in the calculation 
which is likely to vary over time and across different economic areas therefore needs to be used carefully when applied outside of the RIIO-ED1/RIIO-T1 investment period. Another consideration should be the level of investment that is planned to occur over the RIIOED1/RIIO-T1 investment period. RIIO is encouraging investment, innovation and value for money to support the low carbon system. Network companies in other countries have different incentive structures and will have different volumes of network investment requirements, which will affect the actual price $/ \mathrm{km}$ cable which will impact the proxies - meaning a proxy should be developed by region or country.

The approach and method developed in this paper can be applied to other problems in identifying environmental impacts in the construction and other industries. The method can also be applied to impacts other than embodied carbon. For example, other air pollutants or even operational carbon associated with electricity consumption could be considered. Whilst these additional applications are outside the scope of this paper, the method presented here provides a base for further research.

It is anticipated that the proxies developed here will have a number of applications depending on the stakeholder position and role. The proxies will also differ depending on the regulatory or market pressures in place relating to environmental reporting and any financial implication associated with emitting carbon. For the DNO, the proxies would make it possible to initially assess the carbon impacts of different network investment strategies. The proxies also make it possible to identify the impacts of DSM and DG projects in their DNO region for DNO carbon reporting. As environmental pressures grow for commercial organisations, DG owners are increasingly required to assess and report their emissions. Therefore, it is necessary to assess the environmental impact of using their DG before changing the way in which they are run, for example, before entering into contracts with the SO or DNO. In addition to this, DG owners can be legally required to report their carbon emissions and need to understand the impact of their DG when discussing its operation in such reports. For regulatory bodies such as Ofgem, being able to understand the life cycle carbon impacts of different aspects of the transition to a low carbon electricity supply could assist in deciding policies and where to allocate funding for DG or DSM projects.

\section{Future Work}

The model currently averages OHL and UGC, which are the assets with the most accessible data about them.
If extra data were available it would be possible to create more detailed proxy components. The embodied carbon data from [30] could be used to include these assets in the proxy calculations. To date, there is no carbon survey of DNO level assets and therefore Tx data has been used in order to provide an initial calculation as to embodied carbon impacts, and begin to show the regional differences in these impacts within one electricity network. Initially, more data is needed in order to include transformers, substations and other network assets to improve the proxy components. Then, a carbon survey of the DNO assets should be carried out in order to improve the embodied carbon proxy at a Dx and regional level. It is possible that work being undertaken by one of the DNOs in GB Electricity North West, may possibly be applied in order to account for the differences between Tx assets and Dx assets. This work should be extended to include the impact of network upgrades, which is a component not covered in this study due to lack of available data.

The inclusion of operational carbon to the model also brings the need to consider the different times at which carbon is emitted. There is some discussion as to whether the discount rate should be constant or exponential [49]. Because the assumption of linear investment is used in the proxy calculations, the addition of a time value for carbon at this stage of the calculations would be unnecessary, but an important consideration for further work.

\section{Conclusion}

Embodied carbon of network assets is not often considered when investigating network assets. Applying embodied carbon analysis of network assets has shown that each GB DNO region could account for between $15 \mathrm{mTCO}$ and $50 \mathrm{mTCO}$, depending on DNO region, as highlighted in Figure 4 This paper develops and applies two methods to develop regional proxies that may be used to identify the total carbon impacts of different network investment strategies depending on the available data for DNO, shown in Table 9 and SO level, shown in Table 4. Method 1 uses allowable investment, published by the regulator and Method 2 uses investment and new cable requirements as published by the DNOs. Using these proxies, total carbon impacts can be used to analyse the impacts of DSM and DG projects, such as diesel standby generators. Diesel standby generators play a role in many electricity networks globally, through support services provided in conjunction with the SO. These diesel standby generators produce more 
$\mathrm{CO}_{2}$ than other forms of generation, but may play a role in the transition to a lower carbon electricity system.

By identifying regional DNO proxies for the GB market over the RIIO-ED1 period shown in Table 9, this paper has calculated the embodied carbon associated with the planned investment in the GB market during this investment period. Figure 5 shows the calculated embodied carbon emissions of the RIIO-ED1 investment, which have been shown to be as high as $10 \mathrm{kTCO} \mathrm{O}_{2}$ in one DNO region.

Proxies to convert financial investment or peak demand increase to embodied carbon have been calculated by using the network investment data and asset data publicly available for the GB System. The proxies were different depending on the breakdown of network assets as UGC and OHL represent different embodied carbon amounts. These proxies were then applied to both peak demand data and new investment data where available. In both cases, the proxies allowed calculations of embodied carbon impacts throughout an investment planning period. The proxies were also applied in cases where DG or DSM reduces maximum peak demand and therefore this approach has enabled the impact of DG on embodied carbon of the network to be evaluated. It was demonstrated that this approach has value when considering DG units that have local operational emissions that can be a branding or financial negative for the company who own the units.

The paper has explored these issues and applied the proxies to the RIIO-ED1 8 year planning period to assess the impact that an SG unit could have in the embodied emissions of deferred network investment. The paper has shown that in some DNO regions, the standby generator operational emissions can be outweighed by the embodied emissions savings by the reduction in network investment. In some regions it is shown that a DG unit could save 2300TCO $\mathrm{O}_{2}$ over the 8 year RIIO-ED1 planning period. By developing and applying a method to estimate the embodied carbon associated with network investment and its deferral, this paper addresses an issue that has not yet been considered in other literature. The ability to estimate both operational and embodied emissions together when considering electricity networks is vital in quantifying the pathways to transition to a low carbon electricity supply.

\section{Acknowledgements}

The authors would like to thank Marks and Spencer, Matrix Controls Solutions, and the EPSRC for their ongoing support and funding of the Technologies for
Sustainable Built Environments Centre (Grant No. EP/G037787/1).

\section{Nomenclature}

$\triangle P D_{D x} \quad$ Change in Peak Demand at Distribution Level over RIIO-ED1 (kW)

$A E F \quad$ Average Emissions Factor

$C_{D G} \quad$ Distributed Generation Capacity (kW)

$C R C \quad$ Carbon Reduction Commitment

$C S R \quad$ Corporate Social Responsibility

$D G \quad$ Distributed Generation

$D G E \quad$ Displaced Grid Emissions (kg)

$D N O \quad$ Distribution Network Operator

DS M Demand Side Management

Dx Distribution Network

$E E_{D x} \quad$ Distribution Network Embodied Emissions due to RIIO-T1 Investment $(\mathrm{kg})$

$E E_{T x}$ Transmission Network Embodied Emissions due to RIIO-T1 Investment (kg)

$E F_{D G} \quad$ Distributed Generation Emissions Factor $(\mathrm{kg} / \mathrm{kW})$

$E F_{G} \quad$ Grid Emissions Factor $(\mathrm{kg} / \mathrm{kW})$

$E P_{D x 1} \quad$ Distribution Network Emissions Proxy Method $1(\mathrm{~kg} / \mathfrak{f})$

$E P_{D x 2}$ Distribution Network Emissions Proxy Method $2(\mathrm{~kg} / £)$

$E P_{T x}$ Transmission Network Emissions Proxy $(\mathrm{kg} / £)$

$I_{R I I O D x 1} \quad$ RIIO-ED1 Investment Method $1(£)$

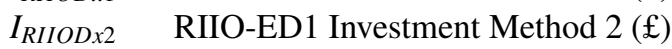

$I_{\text {RIIOTx }} \quad$ RIIO-T1 Investment (£)

$I P_{D x} \quad$ Distribution Network Investment Proxy $(£ / \mathrm{kW})$

$L_{O H L D x} \quad$ Length of Overhead Line in Distribution Network (km)

$L_{O H L T x} \quad$ Length of Overhead Line Network in Transmission Network (km)

$L_{U G C D x} \quad$ Length of Underground Cable in Distribution Network $(\mathrm{km})$

$L_{U G C T x} \quad$ Length of Underground Cable Network in Transmission Network $(\mathrm{km})$

LCA Life Cycle Assessment

$L R I_{\text {RIIOED1 }}$ RIIO-ED1 Load Related Investment (km)

$N C R_{O H L}$ RIIO-ED1 New Cable Requirements for Overhead Lines $(\mathrm{km})$

$N C R_{U G C}$ RIIO-ED1 New Cable Requirements for Underground Cables $(\mathrm{km})$

$O E_{D G} \quad$ Operational Emissions of Distributed Generation $(\mathrm{kg})$

OHL OVerhead Lines 


$\begin{array}{ll}O H L_{\mathrm{CO}_{2}} & \begin{array}{l}\text { Carbon Intensity for Overhead Lines } \\ (\mathrm{kg} / \mathrm{km})\end{array} \\ O H L_{G B P} & \begin{array}{l}\text { Investment Intensity for Overhead Lines } \\ (\mathfrak{k} / \mathrm{km})\end{array} \\ P C_{O H L} & \begin{array}{l}\text { Asset Proxy Component for Overhead } \\ \text { Lines (£/kg) }\end{array} \\ P C_{U G C} & \begin{array}{l}\text { Asset Proxy Component for Underground } \\ \text { Cables (£ } / \mathrm{kg})\end{array} \\ P E F & \text { Peak Emissions Factor } \\ S G & \text { Standby Generator } \\ S O & \text { System Operator } \\ T_{D G} & \text { Run Hours of Distributed Generation (hr) } \\ T x & \text { Transmission Network } \\ U G C & \text { Underground Cables }\end{array}$

\section{References}

[1] Electricity Networks Strategy Group, Our Electricity Transmission Network : A vision for 2020, Tech. Rep. February 2012 (2012).

[2] J. Pecas Lopes, Integration of Dispersed Generation on Distribution Networks - Impact Studies, 2002.

[3] D. T.-C. Wang, L. F. Ochoa, G. P. Harrison, DG Impact on Investment Deferral: Network Planning and Security of Supply. IEEE Transactions on Power Systems 25 (2) (2010) 1134-1141. doi:10.1109/TPWRS.2009.2036361

URL http://ieeexplore.iee.org/lpdocs/epic03/wrapper.htm? arnumber $=5371954$

[4] D. Q. Hung, N. Mithulananthan, R. Bansal, An optimal investment planning framework for multiple distributed generation units in industrial distribution systems Applied Energy 124 (2014) 62-72. doi : 10.1016/j . apenergy.2014.03.005 URL http://linkinghub.elsevier.com/retrieve/pii/ S030626191400227X

[5] D. Zafirakis, K. J. Chalvatzis, G. Baiocchi, G. Daskalakis, Modeling of financial incentives for investments in energy storage systems that promote the large-scale integration of wind energy Applied Energy 105 (2013) 138-154. doi:10.1016/j.apenergy .2012.11.073 URL http://linkinghub.elsevier.com/retrieve/pii/ S0306261912008823

[6] Department of Energy and Climate Change, A Comparison of Emissions Factors for Electricity Generation, Tech. Rep. July (2013).

[7] National Grid, Short Term Operating Reserve Fuel Type Analysis, Tech. rep. (2014).

[8] National Grid, Short Term Operating Reserve Carbon Intensity Report, Tech. rep. (2014).

[9] L. Daniels, B. Potter, P. Coker, Financial Implications of Running Standby Generators in Support of a Smart Grid, in: CISBAT 2013: Cleantech for Smart Cities and Buildings From Urban to Nano Scale, Lausanne, 2013.

[10] Environment Agency, CRC Energy Efficiency Scheme guidance for participants in Phase 2, Tech. Rep. May (2015).

[11] Environment Agency, CRC Energy Efficiency Scheme guidance for participants in Phase 1, Tech. Rep. June 2013 (2013).

[12] H. a. Gil, G. Joos, Models for Quantifying the Economic Benefits of Distributed Generation IEEE Transactions on Power Systems 23 (2) (2008) 327-335. doi:10.1109/TPWRS.2008.920718
URL http://ieeexplore.ieee.org/lpdocs/epic03/wrapper.htm? arnumber $=4494597$

[13] D. Q. Hung, N. Mithulananthan, R. Bansal, Integration of PV and BES units in commercial distribution systems considering energy loss and voltage stability Applied Energy 113 (2014) 1162-1170. doi:10.1016/j.apenergy.2013.08.069 URL http://linkinghub.elsevier.com/retrieve/pii/ S0306261913007137

[14] M. Manfren, P. Caputo, G. Costa, Paradigm shift in urban energy systems through distributed generation: Methods and models Applied Energy 88 (4) (2011) 1032-1048. doi:10.1016/j.apenergy.2010.10.018

URL http://linkinghub.elsevier.com/retrieve/pii/ S0306261910004204

[15] X. Luo, J. Wang, M. Dooner, J. Clarke, Overview of current development in electrical energy storage technologies and the application potential in power system operation Applied Energydoi:10.1016/j.apenergy.2014.09.081 URL http://linkinghub.elsevier.com/retrieve/pii/ S0306261914010290

[16] M. E. Samper, A. Vargas, Investment Decisions in Distribution Networks Under Uncertainty With Distributed Generation Part I : Model Formulation, IEEE Transactions on Power Systems 28 (3) (2013) 2331-2340.

[17] National Renewable Energy Laboratory, State Electricity Regulatory Policy and Distributed Resources : Distribution System Cost Methodologies for Distributed Generation, Tech. Rep. October (2002).

[18] Ofgem, Demand Side Response: A Discussion Paper, Tech. Rep. July (2010)

[19] G. Strbac, C. K. Gan, M. Aunedi, V. Stanojevic, P. Djapic, J. Dejvises, P. Mancarella, A. Hawkes, D. Pudjianto, D. Openshaw, S. Burns, P. West, D. Brogden, A. Creighton, A. Claxton, Benefits of Advanced Smart Metering for Demand Response based Control of Distribution Networks, Tech. Rep. April 2010 (2010).

[20] C. Gu, F. Li, Quantifying the Long-term Benefits of Interruptible Load Scheme for Distribution Network Investment, in: Power and Energy Society General Meeting, 2011 IEEE, 2011, pp. 15.

[21] Z. Hu, F. Li, Cost-Benefit Analyses of Active Distribution Network Management , Part II :, IEEE Transactions on Smart Grid 3 (3) (2012) 1075-1081.

[22] Y. Zhang, C. Gu, S. M. Ieee, F. Li, S. M. Ieee, Evaluation of investment deferral resulting from microgeneration for EHV distribution networks IEEE PES General Meeting (2010) 1-5doi:10.1109/PES. 2010.5589794

URL http://ieeexplore.ieee.org/lpdocs/epic03/wrapper.htm? arnumber $=5589794$

[23] a. Piccolo, P. Siano, Evaluating the Impact of Network Investment Deferral on Distributed Generation Expansion IEEE Transactions on Power Systems 24 (3) (2009) 1559-1567. doi:10.1109/TPWRS.2009.2022973

URL http://ieeexplore.ieee.org/lpdocs/epic03/wrapper.htm? arnumber $=5109478$

[24] H. Gil, G. Joos, On the Quantification of the Network Capacity Deferral Value of Distributed Generation IEEE Transactions on Power Systems 21 (4) (2006) 1592-1599. doi:10.1109/TPWRS. 2006.881158

URL http://ieeexplore.ieee.org/lpdocs/epic03/wrapper.htm? arnumber $=1717560$

[25] V. Méndez, J. Rivier, J. D. L. Fuente, T. Gómez, J. Arceluz, J. Marín, a. Madurga, Impact of distributed generation on distribution investment deferral International Journal of Electrical Power \& Energy Systems 28 (4) (2006) 244-252. doi:10.1016/j.ijepes.2005.11.016 
URL S0142061505001511

[26] M. F. Shaaban, Y. M. Atwa, E. F. El-saadany, DG Allocation for Benefit Maximization in Distribution Networks, IEEE Transactions on Power Systems 28 (2) (2013) 639-649.

[27] National Renewable Energy Laboratory, Cost and Performance Assumptions for Modeling Electricity Generation Technologies, Tech. Rep. November (2010).

[28] World Energy Council, Comparison of Energy Systems Using Life Cycle Assessment, Tech. Rep. July (2004).

[29] R. Turconi, A. Boldrin, T. Astrup, Life cycle assessment (LCA) of electricity generation technologies: Overview, comparability and limitations Renewable and Sustainable Energy Reviews 28 (2013) 555-565. doi : 10.1016/j.rser.2013.08.013 URL http://linkinghub.elsevier.com/retrieve/pii/ S1364032113005534

[30] G. P. Harrison, E. N. J. Maclean, S. Karamanlis, L. F. Ochoa, Life cycle assessment of the transmission network in Great Britain Energy Policy 38 (7) (2010) 3622-3631. doi:10.1016/j.enpol.2010.02.039

URL http://linkinghub.elsevier.com/retrieve/pii/ S0301421510001205

[31] Ofgem, Strategy decision for the RIIO-ED1 electricity distribution price control Overview Final decision Tech. Rep. July (2013).

URL https://www.ofgem.gov.uk/ofgem-publications/47067/ riioed1decoverview.pdf

[32] Ofgem, RIIO-T1 : Final Proposals for National Grid Electricity Transmission and National Grid Gas Cost assessment and uncertainty Supporting Document, Tech. rep. (2012).

[33] Ofgem, Electricity Distribution Price Control Review Final Proposals - Allowed revenue - Cost assessment appendix Document Type : Appendices, Tech. rep. (2009).

[34] G. P. Harrison, A. Piccolo, P. Siano, a. R. Wallace, Exploring the Tradeoffs Between Incentives for Distributed Generation Developers and DNOs IEEE Transactions on Power Systems 22 (2) (2007) 821-828. doi:10.1109/TPWRS . 2007.895176 URL http://ieeexplore.ieee.org/lpdocs/epic03/wrapper.htm? arnumber $=4162598$

[35] Electricity North West, Network Investment Plan 2010-2015, Tech. rep. (2009)

[36] Scottish and Southern Energy Power Distribution, SSE Southern Business Plan Key facts About Our Network, Tech. Rep. April (2013).

[37] Western Power Distribution, WPD East Midlands Business Plan Key Facts, Tech. rep. (2013).

[38] Western Power Distribution, WPD South Wales Business Plan Key Facts about Our Network, Tech. rep. (2013).

[39] Western Power Distribution, WPD South West Business Plan Key Facts About our Network, Tech. rep. (2013)

[40] Northern Powergrid, Northern Powergrid (Yorkshire) plc Business Plan: Key Facts about our Network, Tech. rep.

[41] Western Power Distribution, WPD West Midlands Business Plan Key Facts About our Network, Tech. rep. (2013).

[42] Northern Powergrid, Northern Powergrid (Northeast) Ltd Business Plan: Key Facts About our Network, Tech. rep.

[43] Scottish and Southern Energy Power Distribution, SSE Hydro Business Plan Key Facts About our Network, Tech. Rep. April (2015).

[44] Scottish Power, SP Distribution Business Plan, Tech. rep. (2013).

[45] Scottish Power, SP Manweb Business Plan, Tech. rep. (2013). doi: 10.1117/3.1001180.ch7

[46] Electricity North West, Well Justified Business Plan 2015-2023, Tech. rep. (2014).
[47] UK Power Networks, Our Networks, Your Power: An Introduction to UK Power Networks, Tech. rep. (2012).

[48] National Grid, Electricity Ten Year Statement, Tech. Rep. November (2012).

[49] N. Stern, Stern Review : The Economics of Climate Change, Tech. rep. (2006). 